\title{
NATO HEIDUTUS JA VENEMAA ÄHVARDUS
}

Käesoleva aasta jaanuaris sattus ajakirjanike hambu Donald Trumpi nõunik Kellyanne Conway, kes püüdis välja vabandada Valge Maja pressisekretäri ilmset vassimist, öeldes, et too esitas üksnes „alternatiivseid fakte”. "Alternatiivsed faktid ei ole faktid," irvitasid kommentaatorid, „alternatiivsed faktid on vale." Tegemist on läbipaistva eufemismiga, mis on samaväärne Orwelli „Tõeministeeriumiga” - teatavasti oli selle ainus ülesanne võltsida ajalugu.

Eufemism pole üksnes poliitika ja propaganda tööriist, eufemisme, enamasti mitte nii silmatorkavaid, kohtame igal sammul. Pehmendavat ümberütlemist kasutavad ka toimetajad, kui nad kirjutavad autorile: „Pärast hoolikat kaalumist peame kahetsusega teatama, et Teie artikkel ei vasta meie väljaande profiilile." See tähendab tavaliselt - artikkel ei kõlba kuhugi. Üldiselt seostuvad eufemismid aga ikkagi emotsionaalselt laetud intiimelu sfääridega, nagu seks, keha eritised, surm, puuded, haigused... Nende nimetamine „õige nimega” on paljudes kontekstides tabu. Siin tuleb mängu laiem fenomen, mida tuntakse sõnamaagiana. Kuigi keeleteaduse üks põhiseisukohti on, et häälikujärjendi ja tähenduse suhe on arbitraarne, kaldub suurem jagu inimestest arvama vastupidi. Nad võtavad sõnu, nagu kanduks neissegi edasi nimetatava asja essents. Seepärast määrduvad eufemismid kiiresti ja vaja on üha uusi. Eufemismiveskist, nagu Steven Pinker seda nimetab, ${ }^{1}$ on läbi käinud näiteks ingliskeelsed loo - toilet - bathroom - lavatory - WC gents' - restroom - powder room - comfort station ja nende eestikeelsed vasted

1 S. Pinker, The Stuff of Thought. London: Penguin Books, 2007, lk 320. sitamaja - peldik - kemmerg - kemps käimla - hea koht - tualett -WC-vets... Sama saatus on tabanud nii ingliskeelses maailmas kui ka meie keeleruumis mitmeid teisigi sõnu (näiteks lame - crippled - handicapped - disabled challenged...; sant - invaliid - puudega - erivajadusega...) ja ähvardab meil viimasel ajal neegrit. ${ }^{2}$ See eufemismiveski on töötanud aegade algusest peale. Nii mainib Cicero, et penis 'saba' on olnud viisakam sõna mentula jaoks: „At hodie penis est in obscenis" 'Aga tänapäeval on peenis obstsöönne' („Epistulae ad Familiares” IX, xxii). Sellegipoolest teenivad ladinapõhjalised võõrsõnad, kas või seesama peenis, meid eufemismidena edukalt, eriti meditsiinis, ja esialgu pole märke nende riknemisest.

Uute eufemismide leiutamise kõrval on toimunud 1960. aastatest peale ka üha kiirenev emantsipatsioon, moraalipiirangutest lahtiütlemine ja tabude murdmine. Veel 1960. aastate alguses, kui August Sang kirjutas oma „Rõõmsa laulu”, oli sitt meie trükisõnas tabu. Luuletuse algversioonis olid read: „Ja minust võitu sai mu kodune glavlit. / Laul metsa läks ja tuju on mul sant." Isegi selline kaudne vihje - või ulakus: võib-olla oli rumalam sõna hoopis glavlit - ei läinud Glavlitist, nõukogude tsensuurist, läbi ja tuli otsida uued riimid. Praegu ei ole belletristikas enam sõnakasutusele mingeid piiranguid, transgressiivne kirjandus elatubki kunagistest „rumalatest sõnadest”. ${ }^{3}$ Muidugi,

${ }^{2}$ Vt L. Priimägi, Neegri-küsimusest. Keel ja Kirjandus 2013, nr 1, lk 49-52.

${ }_{3}$ Vt J. Kraavi, Transgresssiivse kirjanduse poeetikast I. Näiteid eesti nüüdiskirjandusest. - Keel ja Kirjandus 2016, nr 11, lk 817-833; J. Kr a a vi, Transgressiivse kirjanduse poeetikast II. Juhtumikäsitlus: 
keelendi stilistiline markeeritus sõltub registrist, milles seda kasutatakse. Nn argikeeles, vabamas suulises keelepruugis pole sitt kunagi tabu olnud. Aga ÕS-is on see siiani varustatud stiilimärgendiga vulg - vulgaarne, kuigi noorte uususes on kõnealusest lekseemist kujunenud tänaseks juba neutraalne määrsõna: sitaks äge, sitaks nõme.

Mõnes valdkonnas on kinnistunud eufemismide valik niigi rikkalik ja vaevalt neid enam juurde sünnib. Nii on suremise kohta üle tosina ümberütleva väljendi: varises manalasse, magab igavest und, läks looja karja, läks parematele jahimaadele, ta on mineja, poeb mätta alla, läks varjuderiiki, viskas lusika nurka, läks teise ilma, leidis igavese rahu, läks mulda, pani kaks kätt rinnale, pani kõrvad pea alla, sirutas koivad välja jne. Seevastu poliitika- ja sotsiaalsfääris vajatakse pidevalt uusi eufemisme, sest kodanikele saab kiiresti selgeks nende tegelik sisu. Hindade reguleerimine või korrigeerimine pole muud kui hindade tõstmine; teabeamet on spionaažikeskus; kui Kapo viib läbi teabehanke, siis ta nuhib kellegi järele; kui Türgi teatab, et tegi kahjutuks 44 ISIS-e võitlejat, siis nad tapeti; kui USA kasutab Guantanamos füüsilist mõjutamist, siis ta piinab vange. Tähtis on fassaad, poliitiline korrektsus.

Arusaamatu on leebus, millega ajakirjandus kohtleb mõnikord kurjategijaid. Sageli räägitakse neist hellalt kui kurikaeltest (vrd võrukael), pahalastest või kurjamitest, kuritegu on mahenenud pättuseks. Samas vaimus nimetati mõne aja eest Vikerraadios politseiniku peksjaid marakrattideks. Siin ei oska arvata muud, kui et ajakirjanikud püüavad iga hinna eest oma keelekasutust rikastada ja kujundlikumaks muuta ning lähevad sellega alt. Kui ilmutada delikaatsust, siis on see põhjendatud haigete või vigaste puhul. Erivajadustega inimest sai juba mainitud. Ka alkohooliku diagnoosimisel väldivad arstid sõna alkohoolik, rääkimata häbistavast joodikust, ja

Kaur Kenderi „Untitled 12”. - Keel ja Kirjandus 2016, nr 12, lk 929-938. kasutavad määratlust alkoholi kuritarvitaja, veel parem - alkoholisõltuvusega patsient. Ja raugad pole enam raugad, vaid eakad või seeniorid. Jõle oleks rääkida raseduse katkestamise asemel sündimata laste tapmisest, nagu teevad mõned vaimulikud.

Kui juttu on eufemismidest, siis ei maksa unustada ka nende vastandeid, düsfemisme. Düsfemism on väljend, mida kasutatakse sihiga solvata või halvustada. Kuigi sellesse kategooriasse on vahel arvatud ka vande- ja sõimusõnad, ${ }^{4}$ on otstarbekam piirduda siin üksnes kaudselt solvavate või halvustavate väljenditega, jäädes niimoodi samale liigitusalusele ja säilitades eufemismide/ düsfemismide sümmeetria. Düsfemismidest pole põhjust rääkida siis, kui sõna on juba oma põhitähenduselt hinnanguline, näiteks halb, loll, kole, lurjus, reetur, pätt jne. Nagu eufemismid, sõltuvad ka düsfemismid kontekstist. Nii on siga neutraalne sõna, kui ta käib kodulooma kohta, negatiivseks, st düsfemismiks, muutub ta siis, kui nii ristitakse inimest. Ilmsete düsfemismidega on tegu, kui mehe kohta öeldakse lilla või naise kohta mära.

Tihti kuuleb halvustavaid repliike opositsioonis olevate poliitikute suust. Üldiselt välditakse nii vängeid väljendeid nagu Rein Raua moraalsed värdjad ja kasutatakse selle asemel kahtlase varjundiga sõnu. Valitsuskoalitsioon on kartell; nad ei sõlmi kokkuleppeid, nagu teeksime meie, vaid teevad diili; nad ei korrasta makse, nagu toimiksime meie, vaid mängivad maksudega; IRL-is intrigeerib mingi poistebänd. (Vastulöök: aga teil on eesotsas poliitbroilerid.) Paljud ideoloogilised eufemismid ja düsfemismid on rahvusvahelises käibes: NATO's intimidation, Russian threat - NATO heidutus, Venemaa ähvardus. Siin on kohane meenutada jälle Bertrand Russelli „ebaregulaarset konjugatsiooni”:

${ }^{4}$ K. Allan, K. Burridge, Euphemism \& Dysphemism. Language Used as Shield and Weapon. New York: Oxford University Press, 1991, lk 26-29. 
mina olen vabameelne

sina oled kergemeelne

tema on amoraalne

mina olen järjekindel

sina oled jonnakas

tema on kiuslik

Kas mingi väljend kujutab endast düsfemismi, sõltub konkreetsest olukorrast ja sellest, kuidas adressaat ütlust tajub. Vahel kutsuvad ka mõned pealtnäha süütud sõnad esile allergilise reaktsiooni. Alates 1970. aastatest on Ameerika feministid püüdnud puhastada keelt sõnadest, mis on nende meelest alandavad, nagu näiteks chairman 'esimees', postman 'postimees', actress 'näitlejanna'. Et juurutada õiget keelekasutust, on välja antud mitmeid käsiraamatuid. ${ }^{5}$ Eesti keeleski on hulgaliselt

${ }^{5}$ Vt näiteks C. Miller, K. Swift, The Handbook of Nonsexist Writing; For writers, seda laadi diskrimineerivaid sõnu: kellamees, keelemees, meremees, peremees, riigimees, jahimees, pillimees, ärimees, tüürimees, kaupmees, kalamees jne. Õnneks on lumemehe kõrval ka lumememm. Mõnel pool on naisõiguslaste võitlus juba vilja kandnud. Nii muudeti hiljuti sooneutraalseks Kanada hümni sõnad: „in all thy sons command” asemel „in all of us command”. Võtkem õppust. Näiteks ootab parandamist Eesti lipulaul, mis algab sedasi: „Kaunistagem Eesti kojad kolme koduvärviga, / mille alla Eesti pojad [!!!] ühiselt võiks koonduda."

JOEL SANG

editors, and speakers. New York: Harper \& Row, 1980; F. Wattman Funk, P. A. Treichler, Language, Gender \& Professional Writing. Theoretical Approaches and Guidlines for Nonsexist Usage. New York: MLA, 1989. 